\section{7th Symposium \\ on Cardiac \\ Arrhythmias}

Payam Safavi-Naeini, MD Abdi Rasekh, MD

\section{CME Credit}

Presented at the 17th Symposium on Cardiac Arrhythmias in Honor of Dr. Ali Massumi, Houston, 20 February 2016.

\section{Section Editor:}

Mohammad Saeed, MD

Key words: Atrial fibrillation/ catheter ablation/instrumentation/methods; equipment design; heart conduction system/ligation/instrumentation

From: Department of Cardiology (Drs. Rasekh and Safavi-Naeini), Texas Heart Institute; and Department of Medicine Section of Cardiology, (Dr. Rasekh), Baylor College of Medicine; Houston, Texas 77030

Address for reprints: Abdi Rasekh, MD, 6624 Fannin St. Houston, TX 77030

E-mail: arasekh@aol.com

(c) 2016 by the Texas Heart ${ }^{\circledR}$ Institute, Houston

\title{
Update on \\ Atrial Fibrillation
}

A trial fibrillation (AF), the most prevalent cardiac arrhythmia, is categorized into 4 different groups on the basis of the duration of the arrhythmia episodes. If AF terminates spontaneously or with intervention within 7 days from onset, it is paroxysmal $A F$; $\mathrm{AF}$ of more than 7 days in duration is persistent $A F$; continuous AF of more than one year's duration is longstanding persistent $A F$; and permanent $A F$ is the condition that ensues when the patient and his or her physician mutually decide not to pursue the restoration or maintenance of sinus rhythm by any means.

Atrial fibrillation is the single most important cause of ischemic stroke, and patients with $\mathrm{AF}$ are 5 times more likely to have a stroke than are those without the condition. ${ }^{2}$ At least $90 \%$ of blood clots responsible for stroke in patients with AF originate from the left atrial appendage (LAA). ${ }^{3}$ Catheter ablation has proved an effective treatment for AF, resulting in approximately a $54 \%$ success rate in paroxysmal and a $42 \%$ in nonparoxysmal types of AF, after a single procedure and at long-term follow-up evaluation. ${ }^{4}$ In this review, we evaluate the possible role of contact force $(\mathrm{CF})$ technology and LAA exclusion to improve the AF ablation outcome.

\section{Carto SmartTouch Technology}

The CARTO ${ }^{\circledR}$ ThermoCool SMART TouCH ${ }^{\circledR}$ Catheter (Biosense Webster, Inc., a Johnson \& Johnson company; Diamond Bar, Calif) is the first therapeutic catheter approved in the United States that has the capability of direct and real-time measurement of CF during the catheter ablation procedure, for the treatment of drug-resistant paroxysmal AF, sustained monomorphic ischemic ventricular tachycardia, or type I atrial flutter. ${ }^{5}$ The paroxysmal-AF catheter ablation trial with a CF-sensing catheter (SMART-AF Trial) was a multicenter (performed at 21 sites in the U.S.), prospective, nonrandomized study that enrolled 172 patients who had histories of at least 3 symptomatic episodes of paroxysmal AF within the previous 6 months, and of at least one antiarrhythmic drug failure. Trial results indicated the safety and increasing success rate of the paroxysmal-AF ablation procedure with use of the THERMOCOOL SMARTTOUCH catheter. ${ }^{5}$

Among the 172 enrolled patients, 161 (mean age, $58.3 \pm 10.93 \mathrm{yr}$ ) began the procedure with catheter insertion; radiofrequency ablation was performed in 160 of these patients, and 117 patients continued the 12-month follow-up protocol, to be evaluated for effectiveness. ${ }^{5}$ The overall success rate of catheter ablation was $74 \%$ at the one-year follow-up evaluation of patients, vs a $66 \%$ success rate at one year when performed out of the selected range. The success rate increased to $81 \%$ when consistent and stable application of $\mathrm{CF}$ was achieved (a targeted range was maintained $\geq 80 \%$ of the time). The SMART-AF trial results showed that the use of CF therapy leads to an improved success rate of $\mathrm{AF}$ ablation procedures for patients undergoing catheter ablation. ${ }^{5}$

\section{TactiCath Quartz Ablation Catheter}

The TactiCath ${ }^{\text {TM }}$ Quartz CF ablation catheter (St. Jude Medical, Inc.; St. Paul, Minn) has improved the efficiency and effectiveness of ablation therapies by providing realtime estimation of the amount of pressure that a catheter tip exerts on heart tissue. ${ }^{6}$ A robust and compelling set of clinical studies then showed the potential of CF in ablation. ${ }^{7-10}$ Data from the TOuCh+ for CATheter Ablation (TOCCATA) and Efficacy Study on Atrial Fibrillation Percutaneous Catheter Ablation with Contact Force Support (EFF ICAS I) trials revealed that a high percentage of pulmonary vein (PV) isolation lesions were ineffective, after a low CF ( $<10 \mathrm{~g})$ had been applied. The data showed 
that contiguous lesions created in accordance with the CF guidelines identified in EFF ICAS I (CF $>10 \mathrm{~g}$ and force-time integral [FTI, area under the real-time CF curve] $>400$, gs) resulted in superior ablation outcomes, with durable PV isolation of up to $98 \%$ at 3 months via invasive follow-up (isolation or reconnection of each vein was evaluated via diagnostic catheter). Several other study investigators subsequently showed the importance of FTI as a determinant for ablation success or for a reduction of procedure time. The EFF ICAS II ${ }^{9}$ study confirmed that maintaining adequate $\mathrm{CF}$ levels (target CF, $20 \mathrm{~g}$; and minimum FTI, $400 \mathrm{gs}$ ) resulted in improving PV-isolation durability at 3 months' follow-up evaluation - an 85\% success rate in EFF ICAS II, compared with $71 \%$ in EFF ICAS I. In the TactiCath Contact Force Ablation Catheter Study for Atrial Fibrillation (TOCCASTAR), $85.5 \%$ of the patients who had an AF ablation with optimal CF parameters were free of AF after 12 months, whereas the success rate was $67.7 \%$ among patients who had an AF ablation without optimal CF.1 ${ }^{10}$

\section{The aMAZE Trial}

The results of Left Atrial Appendage Ligation and Ablation for Persistent Atrial Fibrillation study (the LAALA-AF Registry ${ }^{11}$ and other independent studies ${ }^{12}$ have introduced the possible role of the LARIAT ${ }^{\circledR}$ Suture Delivery Device (SentreHEarT, Inc.; Redwood City, Calif) ligation in decreasing the burden of arrhythmia in patients who have AF. Lakkireddy and colleagues ${ }^{11}$ observed that the atrial arrhythmia burden decreased from $81 \%$ to $47 \%$ three months after the LAA ligation. In Afzal and associates' study, ${ }^{12}$ significant reductions in AF burden were reported in patients with known AF triggers inside the LAA $(n=9)$ at 3 -month $(52 \% \pm 35 \%)$ and 12 -month ( $42 \% \pm 19 \%)$ follow-up evaluations, in comparison with the respective baseline figures $(84 \% \pm$ $31 \% ; P<0.0001)$. The LAA Ligation Adjunctive to PVI for Persistent or Longstanding Persistent Atrial Fibrillation (aMAZE) Trial to Evaluate LARIAT Ligation of the Left Atrial Appendage ${ }^{13}$ is designed to evaluate the success rate of $A F$ ablation with and without concomitant LAA exclusion.

The aMAZE Trial is a prospective, multicenter, randomized (2:1), controlled study that will be conducted among patients, 18 to 80 years of age, with documented persistent or longstanding persistent $\mathrm{AF}(<3 \mathrm{yr}$ of continuous AF) scheduled for catheter ablation. This study will be done in 2 stages: in stage 1 (Limited Early Stage), up to 175 subjects will be recruited at approximately 15 sites, and for stage 2 (Pivotal Stage), as many as 600 subjects will be enrolled at up to 50 sites. All patients from both stages will be included in the primary analysis. ${ }^{13}$

\section{Conclusion}

Force-sensing improves the efficacy of PV isolation when ablation is performed at optimal CF. Multiple investigators have shown the clinical benefits of mechanical and electrical isolation of the LAA with the LARIAT. The aMAZE trial investigators will study the importance of adjunctive electrical isolation of LAA in persistent $\mathrm{AF}$.

\section{References}

1. January CT, Wann LS, Alpert JS, Calkins H, Cigarroa JE, Cleveland JC Jr, et al. 2014 AHA/ACC/HRS guideline for the management of patients with atrial fibrillation: a report of the American College of Cardiology/American Heart Association Task Force on Practice Guidelines and the Heart Rhythm Society [published erratum appears in J Am Coll Cardiol 2014; 64(21):2305-7]. J Am Coll Cardiol 2014;64(21):e1-76.

2. Lubitz SA, Rosen AB, Ellinor PT, Benjamin EJ. Stroke risk in AF: do AF patterns matter? Eur Heart J 2010;31(8):908-10.

3. Whitlock RP, Healey JS, Connolly SJ. Left atrial appendage occlusion does not eliminate the need for warfarin. Circulation 2009;120(19):1927-32.

4. Ganesan AN, Shipp NJ, Brooks AG, Kuklik P, Lau DH, Lim HS, et al. Long-term outcomes of catheter ablation of atrial fibrillation: a systematic review and meta-analysis. J Am Heart Assoc 2013;2(2):e004549.

5. Natale A, Reddy VY, Monir G, Wilber DJ, Lindsay BD, McElderry HT, et al. Paroxysmal AF catheter ablation with a contact force sensing catheter: results of the prospective, multicenter SMART-AF trial. J Am Coll Cardiol 2014;64(7):64756.

6. Kuck KH, Reddy VY, Schmidt B, Natale A, Neuzil P, Saoudi $\mathrm{N}$, et al. A novel radiofrequency ablation catheter using contact force sensing: Toccata study. Heart Rhythm 2012;9(1): 18-23.

7. Reddy VY, Shah D, Kautzner J, Schmidt B, Saoudi N, Herrera $\mathrm{C}$, et al. The relationship between contact force and clinical outcome during radiofrequency catheter ablation of atrial fibrillation in the TOCCATA study. Heart Rhythm 2012;9 (11):1789-95.

8. Neuzil P, Reddy VY, Kautzner J, Petru J, Wichterle D, Shah $\mathrm{D}$, et al. Electrical reconnection after pulmonary vein isolation is contingent on contact force during initial treatment: results from the EFFICAS I study. Circ Arrhythm Electrophysiol 2013;6(2):327-33.

9. Kautzner J, Neuzil P, Lambert H, Peichl P, Petru J, Cihak R, et al. EFFICAS II: optimization of catheter contact force improves outcome of pulmonary vein isolation for paroxysmal atrial fibrillation. Europace 2015;17(8):1229-35.

10. Reddy VY, Dukkipati SR, Neuzil P, Natale A, Albenque J, Kautzner J, et al. Randomized, controlled trial of the safety and effectiveness of a contact force-sensing irrigated catheter for ablation of paroxysmal atrial fibrillation: results of the TactiCath Contact Force Ablation Catheter Study for Atrial Fibrillation (TOCCASTAR) Study. Circulation 2015;132(10): 907-15.

11. Lakkireddy DR, Earnest M, Janga P, Reddy M, Vallakati A, Nath J, et al. Effect of endoepicardial percutaneous left atrial appendage ligation (LARIAT) on arrhythmia burden in patients with atrial fibrillation [abstract]. J Am Coll Cardiol 2013;61(10_S):E385. Available from: http://Content.online jacc.org/article.aspx?articleid=1664532\&resultClick=3.

12. Afzal MR, Kanmanthareddy A, Earnest M, Reddy M, Atkins D, Bommana $S$, et al. Impact of left atrial appendage exclusion using an epicardial ligation system (LARIAT) on atrial fibrillation burden in patients with cardiac implantable electronic devices. Heart Rhythm 2015;12(1):52-9. 
13. aMAZE Study: LAA ligation adjunctive to PVI for persistent or longstanding persistent atrial fibrillation (aMAZE). Available from: https://clinicaltrials.gov/ct2/show/NCT02513797 [updated 2016 Apr 28; cited 2016 Aug 12]. 